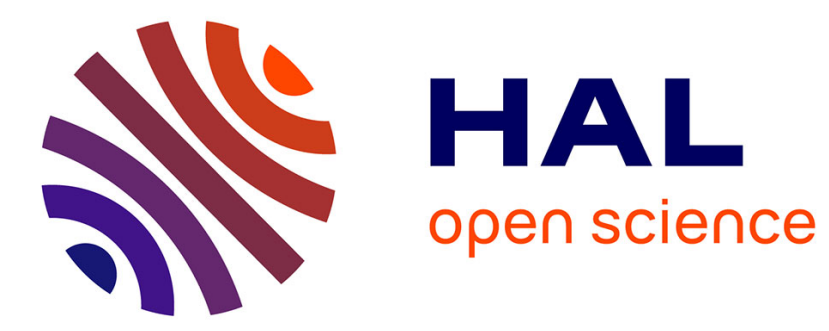

\title{
A new pigment type: Colored diblock copolymer-mica composites
}

L. Ghannam, H. Garay, M.E.R. Shanahan, Jeanne François, Laurent Billon

\section{To cite this version:}

L. Ghannam, H. Garay, M.E.R. Shanahan, Jeanne François, Laurent Billon. A new pigment type: Colored diblock copolymer-mica composites. Chemistry of Materials, 2005, 17 (15), pp.3837-3843. $10.1021 / \mathrm{cm} 0478024$. hal-01582050

\section{HAL Id: hal-01582050 https://hal.science/hal-01582050}

Submitted on 1 Jun 2021

HAL is a multi-disciplinary open access archive for the deposit and dissemination of scientific research documents, whether they are published or not. The documents may come from teaching and research institutions in France or abroad, or from public or private research centers.
L'archive ouverte pluridisciplinaire HAL, est destinée au dépôt et à la diffusion de documents scientifiques de niveau recherche, publiés ou non, émanant des établissements d'enseignement et de recherche français ou étrangers, des laboratoires publics ou privés. 


\title{
A New Pigment Type: Colored Diblock Copolymer-Mica Composites
}

\author{
Leïla Ghannam, ${ }^{\dagger, \ddagger}$ Hélène Garay,$^{\dagger}$ Martin E. R. Shanahan ${ }^{\dagger}{ }^{\dagger}$ Jeanne François, ${ }^{\dagger}$ and \\ Laurent Billon*,\$ \\ Centre de Matériaux de Grande Diffusion, Ecole de Mines d'Alès-Pau, and Laboratoire de \\ Physico-chimie des Polymères, UMR 5067 CNRS, Université de Pau et Pays de l'Adour, \\ Hélioparc Pau-Pyrénées, 2 avenue Président Angot, 64053 PAU CEDEX 9, France
}

\begin{abstract}
New mica-polymer composite pigments have been prepared and characterized. The pigments are prepared from mica surfaces by block copolymerization of butyl acrylate (BA) and a mixture of styrene (S) and a modified alizarin (A; dye). This is performed after physical adsorption of a radical initiator with a cationic group. Some of the copolymer was desorbed from the surface and characterized by ${ }^{1} \mathrm{H}$ NMR, size exclusion chromatography, and UV-visible spectroscopy. This desorbed copolymer fraction had a number-average molecular weight of $140000 \mathrm{~g} \cdot \mathrm{mol}^{-1}$ with chemical compositions of $16 \%$ and $84 \% \mathrm{M}$, respectively, of poly(butyl acrylate) (PBA) and poly(styrene-alizarin) [P(S-A)]. In addition, it had a yellow coloration when in the bulk form. The remaining mica composites were characterized by Fourier transform infrared spectroscopy, thermogravimetric analysis, and X-ray diffraction. It was found that 0.07 molecules of block copolymer per $\mathrm{nm}^{2}$ of mica remained adsorbed on the mica surface. This leads to a surprising pink color, which may be explained by the basicity of the mica surface due to the $\mathrm{pH}-$ color-sensitive character of the alizarin dye.
\end{abstract}

\section{Introduction}

Recently polymer-based inorganic/organic composites have been given more attention. For example, the study of polymer-silicate systems is a very active field of research in polymer and material science. ${ }^{1}$ The development of such materials aimed generally to improve the properties of polymers, such as mechanical behavior, ${ }^{2}$ thermal stability, ${ }^{3}$ and flame retardancy, ${ }^{4}$ with or without exfoliation of silicate by polymers. The general purpose of the work presented here is the development of new organic/inorganic composites that are able to exhibit special visual aspects. Indeed, the control of color plays an important role in the conception of products and objects of daily life (cosmetics, tissues, painted papers, ceramics, etc.). In this field, incorporation of dyes in a variety of materials has been already investigated in various systems such as membrane filters, ${ }^{5}$ inorganic particles, ${ }^{6}$ clay, ${ }^{7}$ and DNA. ${ }^{8}$

* Corresponding author. Tel.: 33 (0) 5-59-40-76.09. Fax: 33 (0) 5-59-4076-23. E-mail: laurent.billon@univ-pau.fr.

† Centre de Matériaux de Grande Diffusion, Université de Pau et Pays de l'Adour.

¥ Laboratoire de Physico-chimie des Polymères, Université de Pau et Pays de l'Adour.

(1) (a) Heinz, H.; Castelijns, H. J.; Suter, U. W. J. Am. Chem. Soc. 2003, 125, 9500. (b) Polymer-Clay Nanocomposites; Pinnavaia, T. J., Beall, G. W., Eds.; Wiley: New York, 2000. (c) Carrado, K. A. PolymerClay Nanocomposites. In Advanced Polymeric Materials: structure property relationships; Advani, S. G., Shonaike, G. O., Eds.; CRC Press: Boca Raton, FL, 2003; p 349.

(2) (a) Lan, T.; Pinnavaia, T. J. Chem. Mater. 1994, 6, 2216. (b) Wang, Z.; Pinnavaia, T. Chem. Mater. 1998, 10, 1820.

(3) Messersmith, P.; Giannelis, E. P. Chem. Mater. 1994, 6, 1719

(4) (a) Wang, J.; Du, J.; Zhu, J.; Wilkie, C. A. Polym. Degrad. Stab. 2002, 77, 249. (b) Zhu, J.; Uhl, F. M.; Morgan, A. B.; Wilkie, C. A. Chem. Mater. 2001, 13, 4649.

(5) (a) Kost, S. H.; Breuer, H. D. J. Phys. Chem. 1992, 96, 134. (b) Scharz, G.; Balthazar, W. Eur. J. Biochem. 1970, 12, 461.
The visual aspect of materials 9,10 is not simply limited to the classical effects of light absorption and reflection. The origin of such appearances is the existence of highly ordered structures in materials. Industries are now looking for more sophisticated appearances to improve the impact of their products which may include iridescence or color changes with external factors such as temperature and moisture.

Basically, the pigments used in industrial applications can be divided into three groups according to their interaction with light: traditional pigments, metallic pigments, and pearlescent and interference pigments. Synthetic pearlescent pigments are either transparent or light-absorbing plateletshaped crystals. They can be in multilayered structures in which the layers have different refractive indixes and light absorption properties. ${ }^{11-13}$

Our work intends to reproduce a multilayered structure by creating at the surface of a lamellar silicate or clay the superposition of two layers of organic compounds. In this paper, as in the case of inorganic compounds among the various clays (montmorillonite, silica, talc, mica, etc.), mica was chosen for the application. Mica is a chemically inert alumino-silicate mineral. Its crystalline structure consists

(6) Sheppard, S. E.; Lambert, R. H.; Walker, R. D. J. Chem. Phys. 1996, 7, 265.

(7) Ogawa, M. Photoprocesses in clay-organic complexes. In Handbook of Layered Materials; Auerbach S. M., Carrodo, K. A., Dutta, P. K., Eds.; Marcel Dekker: New York, 2004.

(8) Bunting, R. J.; Phan, T. V.; Komali, E.; Bowhen, R. M. Biophys. J. 1989, 56, 979.

(9) Dutt, M. K. Indian J. Exp. Biol. 1980, 18, 57.

(10) Ray, S. S.; Okamoto, M. Prog. Polym. Sci. 2003, 28, 1539.

(11) Rodrigues, A. B. ASTM Standardization News; American Society for Testing Materials: Philadelphia, October, 1995.

(12) Bäumer, W. Farbe lack 1973, 79, 647.

(13) Plaff, G.; Reynders, P. Chem. Rev. 1999, 99, 1963. 


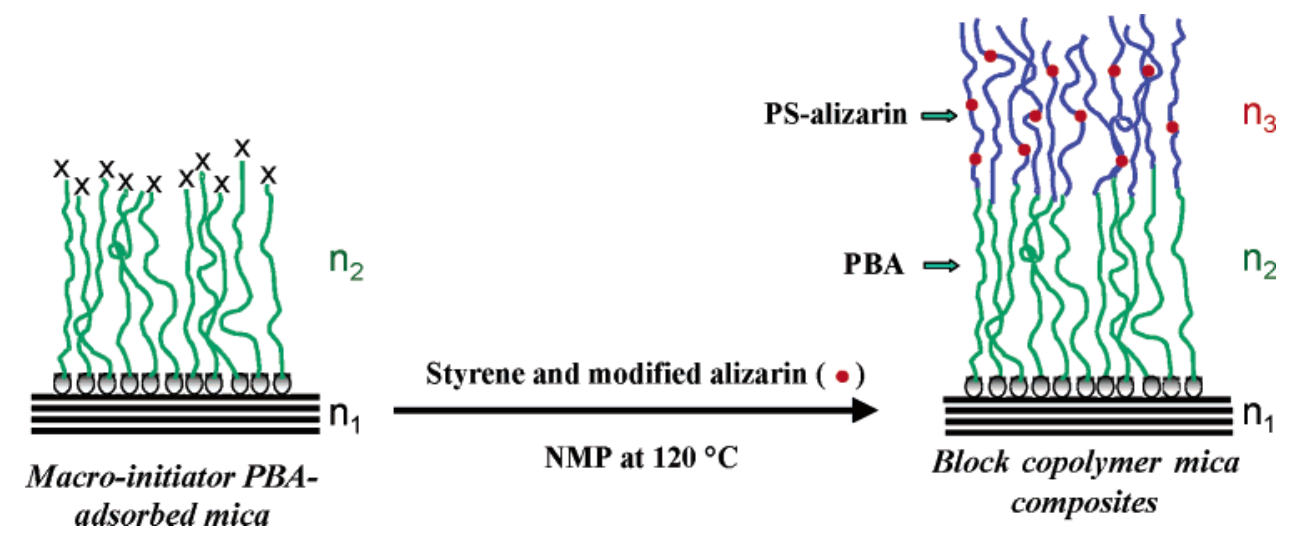

${ }^{a} n_{1}, n_{2}$, and $n_{3}$ correspond to the refractive indexes of the three layers of the composite.

of preliminary negatively charged 2:1 layers whose charges are compensated by interlayer cations [monovalent $\left(\mathrm{Na}^{+}, \mathrm{K}^{+}\right.$, etc.) or divalent $\left(\mathrm{Ca}^{2+}, \mathrm{Mg}^{2+}\right.$, etc. $\left.)\right] .{ }^{14}$ Each 2:1 layer consists of two tetrahedral sheets sandwiching one octahedral sheet. Because of its lamellar structure, mica has been extensively studied. It can as well be found under the form of small platelets which have for a long time attracted attention for use in cosmetic products, in particular. One of the important features of mica flakes is that they conserve their lamellar structure under different conditions. ${ }^{15}$

The elaboration of a multilayered composite by block copolymerization from the mica surface of two polymer sequences is considered here for the first time. More precisely, the first sequence is the homo PBA, and the second one is a statistical copolymer of styrene and a vinyl monomer bearing a chromophore group [alizarin, derivative A; $\mathrm{P}(\mathrm{S}-$ A)]. The presence of a chromophore group allows absorption. On the other hand, a strong segregation between the PBA and $\mathrm{P}(\mathrm{S}-\mathrm{A})$ sequences is expected because they differ significantly by their solubility parameters and should be incompatible. ${ }^{26}$

In a previous paper, the possibility of synthesizing PBA from the surface of mica platelets has already been demonstrated. ${ }^{16}$ To create a homogeneous brush of PBA, an initiator possessing a cationic function that is able to interact with the negative charge of mica is adsorbed on its surface. Then a nitroxide-mediated polymerization ${ }^{17}$ (NMP), belonging to the stable free radical polymerization (SFRP) processes, is used to polymerize butyl acrylate (BA). SFRP is particularly attractive for industrial applications due to its efficiency for preparing homopolymeric samples of low polydispersity index and its ability to prepare block copolymers which were in the past obtained by other methods such as anionic, ${ }^{18}$ cationic, ${ }^{19}$ and group transfer polymerization. ${ }^{20}$ Apart from

(14) Bailey, S. W. Reviews in Mineralogy; Virginia Polytechnic Institute and State University: Blacksburg, 1984; Vol. 13, p 1.

(15) (a) Weiss, A. Z. Anorg. Allg. Chem. 1958, 297, 232. (b) Gaines, G. L.; Rutkowski, C. P. J. Phys. Chem. 1957, 61, 1439. (c) Pashley, R. M. J. Colloid Interface Sci. 1981, 80, 153.

(16) Ghannam, L.; Bacou, M.; Garay, H.; Francois, J.; Shanahan, M. E. R.; Billon, L. Polymer 2004, 45, 7035.

(17) (a) Georges, M. K.; Veregin, R. N.; Kazmaier, P. M.; Hamer, G. K. Macromolecules 1993, 26, 2987. (b) Mardare, D.; Matyjaszewski, K. Polym. Prepr., ACS Polym. Div. 1994, 35, 557.

(18) Szwarc, M. Carbanion living polymers electron transfer process; Interscience: New York, 1968.
NMP, other SFRP approaches have also been developed such as atom transfer radical polymerization ${ }^{21,22}$ and reversible addition-fragmentation chain transfer ${ }^{23}$.

In the present work, we exploit the capacity of NMP for providing block copolymers. It is known that a PBA "living" chain end can initiate the polymerization of styrene from an inorganic silica surface. ${ }^{26}$ The preparation of mica/block copolymer composites then requires the following steps: modification of the dye (alizarin) to prepare a vinyl monomer able to copolymerize with styrene, polymerization of BA on a mica surface after adsorption of a cationic initiator, and polymerization of a statistical copolymer of styrene and the modified dye monomers from the PBA used as a macroinitiator. The latter step is presented in Scheme 1.

This paper describes the various methods used in each of the previously listed steps as well as the chemical characterization of the composites obtained using complementary techniques [size exclusion chromatography (SEC), nuclear magnetic resonance (NMR), Fourier transform infrared (FTIR), thermogravimetric analysis (TGA), differential scanning calorimetry (DSC), and X-ray diffraction (XRD)]. The possibility of preparing mica-based systems incorporating organic multilayered block copolymers at the platelet surface without interfoliation of mica is demonstrated. Preliminary results on the visual aspects of these composites are also given.

\section{Experimental Section}

2.1. Materials. The Soft Mica samples were received from the Comptoir des Minéraux et des Matières Premières (CMMP, France). The physicochemical characteristics of this mica are given in Table 1.

The monomers (Aldrich) and solvents mentioned in the present paper were used as received.

(19) Matyjaszewski, K. Cationic polymerizations; mechanisms, synthesis and applications; Marcel Dekker: New York, 1996.

(20) Webster, O. W.; Hertler, W. R.; Sogah, D. Y.; Farnham, W. B.; Rajan Babu, T. V. J. Am. Chem. Soc. 1983, 105, 5706.

(21) (a) Wang, J. S.; Matyjaszewski, K. J. Am. Chem. Soc. 1995, 117, 5614. (b) Matyjaszewski, K.; Wang, J. S. Macromolecules 1995, 28, 7901.

(22) (a) Granel, C.; Dubois, Ph.; Jérome, R.; Teyssié, Ph. Macromolecules 1996, 29, 8576. (b) Matyjaszewski, K. ACS Symp. Ser. 1998, 685, 258.

(23) Chong, Y. K.; Le, T. P. T.; Moad, G.; Rizzardo, E.; Thang, S. H. Macromolecules 1999, 32, 2071. 
Table 1. Physicochemical Characteristics of the Mica Used

\begin{tabular}{cr}
\hline chemical analysis $(\%)$ & \\
\hline $\mathrm{SiO}_{2}$ & 49.2 \\
$\mathrm{Al}_{2} \mathrm{O}_{3}$ & 28.3 \\
$\mathrm{~K}_{2} \mathrm{O}$ & 9.8 \\
$\mathrm{Fe}_{2} \mathrm{O}_{3}$ & 6.9 \\
$\mathrm{Na}_{2} \mathrm{O}$ & 0.8 \\
$\mathrm{CaO}$ & 1 \\
$\mathrm{H}_{2} \mathrm{O}$ & 0.2 \\
& \\
\hline physical properties & \\
\hline density $\left(\mathrm{g} / \mathrm{cm}^{3}\right)$ & 2.80 \\
pH (in water) & 9 \\
average particle $\operatorname{size}^{2}(\mu \mathrm{m})$ & $45-150$ \\
specific surface $\left(\mathrm{m}^{2} / \mathrm{g}\right)$ & 5.9
\end{tabular}

Scheme 2. Chemical Modification of the Alizarin Dye

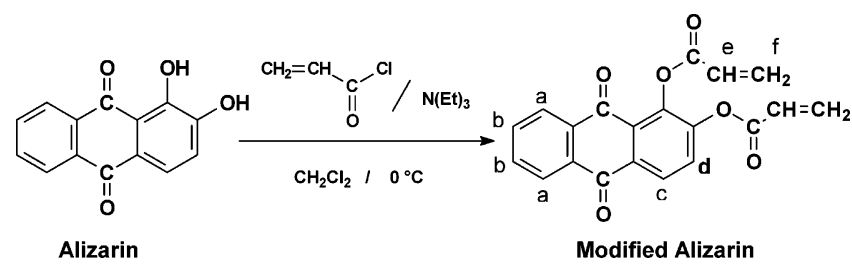

The dye chosen for this study is "alizarin" which is an anthraquinon whose structure is discussed below.

2.2. Synthesis. Alizarin Modification. To incorporate chromophore groups in the polymer chains, it was necessary to prepare alizarin-based vinyl monomers. ${ }^{24}$ The experimental method is described by van Werne et al. ${ }^{25}$ and corresponds to Scheme 2 . The average number of acrylic units per molecule of alizarin calculated by ${ }^{1} \mathrm{H}$ NMR is 0.5 .

Polymerization on the Mica Surface. To obtain poly (n-butyl acrylate)- $b$-(styrene-alizarin) [poly(BA- $b-(\mathrm{S}-\mathrm{A}))]$ at the surface of the mica, two phases are necessary: (i) modification of the mica surface by a macroinitiator of PBA using NMP of BA, as previously described, ${ }^{16}$ and (ii) the steps schematized in Scheme 2 where styrene and modified dye are copolymerized from the PBA macroinitiator.

For this purpose, a mixture of mica particles with adsorbed PBA $(100 \mathrm{mg})$, styrene (estimated ratio $[\mathrm{S}] /[\mathrm{PBA}]=30000)$ and modified dye $([\mathrm{S}] /[$ alizarin $]=333)$ was heated at $120{ }^{\circ} \mathrm{C}$ for $2 \mathrm{~h}$. Here, the re-initiation of the PBA was performed to exploit the ability of the NMP to form block copolymers, knowing that the polymerization would not be controlled with a high $[\mathrm{S}] /[\mathrm{PBA}]$ ratio.

After reaction, the dispersion was poured into ethanol to precipitate both free polymer and mica with adsorbed polymer. Following filtration and drying, the polymer-mica mixture was extracted several times with toluene to remove the nonadsorbed polymer. Two types of copolymer were found: copolymer "bound" to the mica (not removed from the mica either during polymerization or by toluene extraction) and free copolymer precipitated in ethanol. The solid phase which consisted of mica covered by adsorbed polymer was dried at room temperature under vacuum.

(24) The alizarin dye $(40.95 \mathrm{mmol})$ was mixed in the presence of triethylamine $\left(52.3 \times 10^{-3} \mathrm{~mol}\right)$ in $157 \mathrm{~mL}$ of $\mathrm{CH}_{2} \mathrm{Cl}_{2}$ solution and cooled to $0{ }^{\circ} \mathrm{C}$ in an ice bath. The mixture was degassed with nitrogen, and the acryloyl chloride $\left(\mathrm{C}_{3} \mathrm{H}_{3} \mathrm{OCl} ; 61.55 \mathrm{mmol}\right)$ was added dropwise Upon complete addition, the mixture was stirred for $1 \mathrm{~h}$ at $0{ }^{\circ} \mathrm{C}$ and then brought to room temperature and stirred for $24 \mathrm{~h}$. After filtration, the product was washed several times with water and dried under vacuum. The average number of acrylic units per alizarin calculated by ${ }^{1} \mathrm{H}$ NMR is $50 \%$.

(25) Von Werne, T.; Patten, T. E. J. Am. Chem. Soc. 2001, 123, 7497.

(26) Laruelle, G.; Parvole, J.; François, J.; Billon, L. Polymer 2004, 45, 5013.

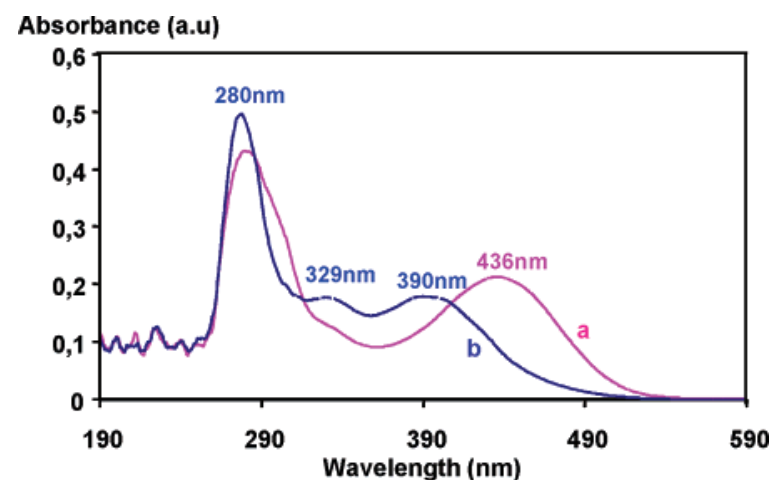

Figure 1. UV-vis spectra of alizarin (a) before and (b) after chemical modification.

2.3. Characterization Methods. ${ }^{l} H$ NMR. ${ }^{1} \mathrm{H}$ NMR spectra were recorded at $400 \mathrm{MHz}$ on a Bruker Advanced AM400 spectrometer in $\mathrm{CDCl}_{3}$, and the chemical shifts $(\delta)$ in ppm were referenced to internal tetramethylsilane.

FTIR Spectroscopy. FTIR spectra were recorded using a Bruker IFS $66 / \mathrm{S}$ spectrometer at a resolution of $4 \mathrm{~cm}^{-1}$ in absorption mode (KBr films) and 100-1000 scans were accumulated.

$U V$-Visible Spectroscopy. UV-visible spectra were recorded using a Shimadzu UV-2101 PC spectrometer.

TGA. TGA was carried out using a System TA 2950 apparatus to determine the amount of bound polymer chains adsorbed onto the mica surface in a temperature range of $30-800{ }^{\circ} \mathrm{C}$ at a scan rate of $10{ }^{\circ} \mathrm{C} / \mathrm{min}$ in air.

Glass transition temperatures $\left(T_{\mathrm{g}}\right)$ were measured using a differential scanning calorimeter, TA series-[Q100]. Samples $(\sim 5$ $\mathrm{mg}$ ) were weighed and scanned at $20{ }^{\circ} \mathrm{C} / \mathrm{min}$ under dry nitrogen (flow rate: $50 \mathrm{~mL} / \mathrm{min}$ ) for both heating and cooling. The reported glass transition temperatures were determined from the second heating run and were taken as the midpoint of the $\Delta H / \mathrm{d} t$ step in the DSC spectra.

The molecular weights and the polydispersity indexes of the free polymer were determined by SEC, using a 2690 Waters System with tetrahydrofuran as the mobile phase. Molecular weights were calculated relative to polystyrene (PS) standards.

The XRD data from powder samples were recorded using reflection geometry with pseudo-focusing known as BraggBrentano. They were collected at room temperature on an INEL CPS 120 powder diffractometer [calibrated with NAC $\left(\mathrm{Na}_{2} \mathrm{Ca}_{3}-\right.$ $\left.\mathrm{Al}_{2} \mathrm{~F}_{14}\right)$ ] with monochromatized $\mathrm{Cu} \mathrm{K \alpha}\left(\lambda_{\text {measure }}=0.15406 \mathrm{~nm}\right)$ radiation $(30-40 \mathrm{kV})$.

\section{Results and Discussion}

3.1. Characterization of the Alizarin-Based Monomer. The comparison of ultraviolet-visible (UV-vis) absorption spectra of alizarin before and after chemical modification, represented in Figure 1, shows that the absorption band of $\mathrm{C}=\mathrm{O}$ at $436 \mathrm{~nm}$ shifts to $390 \mathrm{~nm}$ and a new absorption band appears at $329 \mathrm{~nm}$, characteristic of $\mathrm{C}=\mathrm{C}$. Moreover, in these partially conjugated systems, we are most likely to observe the changes that arise from the modification of the whole extended electronic system and not merely from localized changes. This demonstrates qualitatively that modification was successfully made.

The FTIR spectrum of modified alizarin shows the vibration band characteristic of the carbonyl function at 1749 $\mathrm{cm}^{-1}\left(v_{\mathrm{C}=0}\right)$ to be in agreement with the results of $\mathrm{UV}-\mathrm{vis}$ spectroscopy. 


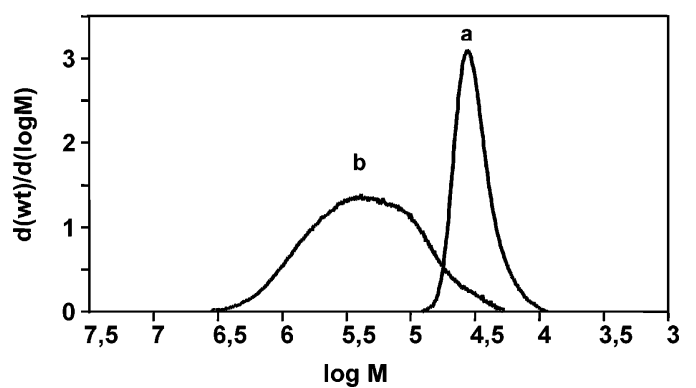

Figure 2. SEC curves of the (a) macroinitiator and (b) its corresponding diblock copolymer BA- $b-(\mathrm{S}-\mathrm{A})$.

Table 2. Apparent Molecular Weight and Polydispersity Index of PBA Macroinitiator and Diblock Copolymer BA- $b-(\mathrm{S}-\mathrm{A})$ by SEC

\begin{tabular}{ccc}
\hline & $M_{\mathrm{n}}(\mathrm{g} / \mathrm{mol})$ & $I_{\mathrm{p}}{ }^{a}$ \\
\hline PBA macroinitiator & 30000 & 1.14 \\
diblock copolymer & 157000 & 2.29 \\
${ }^{a} I_{\mathrm{p}}:$ polydispersity index $M_{\mathrm{w}} / M_{\mathrm{n}}$. & &
\end{tabular}

A complementary NMR study was performed in dimethyl sulfoxide solvent. ${ }^{1} \mathrm{H}$ NMR: $\delta=8.2\left(\mathrm{H}_{a}\right)$ and $7.9\left(\mathrm{H}_{b}\right), 7.7$ $\left(\mathrm{H}_{c}\right), 7.4\left(\mathrm{H}_{d}\right), 6.2\left(\mathrm{CH}_{e}\right)$, and $6.6\left(\mathrm{CH}_{2 f}\right) .{ }^{13} \mathrm{C}$ NMR shows the appearance of resonance at $166 \mathrm{ppm}$, characteristic of the carbonyl function, and at 130 and 128 ppm corresponding respectively to $\mathrm{CH}$ and $\mathrm{CH}_{2}$ of the acrylic function, thus, confirming the success of alizarin modification. Nevertheless, the average number of acrylic units per alizarin molecule was calculated to 0.5 by ${ }^{1} \mathrm{H}$ NMR. This spectrum shows $10 \%$ of residual alizarin and the presence of two mono-modified alizarin structures in the proportion of 35/65 for ortho/metamodified hydroxyl groups (Supporting Information). The free alizarin can be easily eliminated during the process of extraction of the unbound polymer. Moreover, it is important to note that the bi-modification of the alizarin hydroxyl functions at the low, trace level can be neither demonstrated nor neglected.

3.2. Characterization of Free Copolymer. SEC. Initially, the apparent number-average molecular weight as well as the molar mass distribution of both the macroinitiator and the free copolymer desorbed from the mica surface during reaction were measured by SEC. The chromatograms of the PBA macroinitiator and of the free diblock copolymer can be compared in Figure 2. The values of the number-average molecular weight (PS equivalent) are reported in Table 2.

It is clear that the PBA precursor continued to polymerize with the other monomers. The final block copolymer shows neither shoulder nor peak in the low molecular weight range, indicating the extension efficiency of the first block to form a diblock copolymer. Moreover, even if some overlap occurs between the two chromatograms in a low molecular weight range that corresponds to a low percentile of dead chains $(<5 \%)$, a high polydispersity value was obtained for the diblock copolymer. Also, the experimental $M_{\mathrm{n}}$ was lower than the theoretical one $\left(3 \times 10^{6} \mathrm{~g} / \mathrm{mol}\right.$ at complete conversion). This result may be explained by (i) the presence of two polymerizable groups on alizarin, which can induce ramification of the PS chains and formation of soluble nonlinear chains, (ii) the uncontrolled radical polymerization due to the high initial ratio $[\mathrm{S}] /[\mathrm{PBA}]$, and (iii) the chemical structure of the dye. Indeed, quinine derivates are used as a

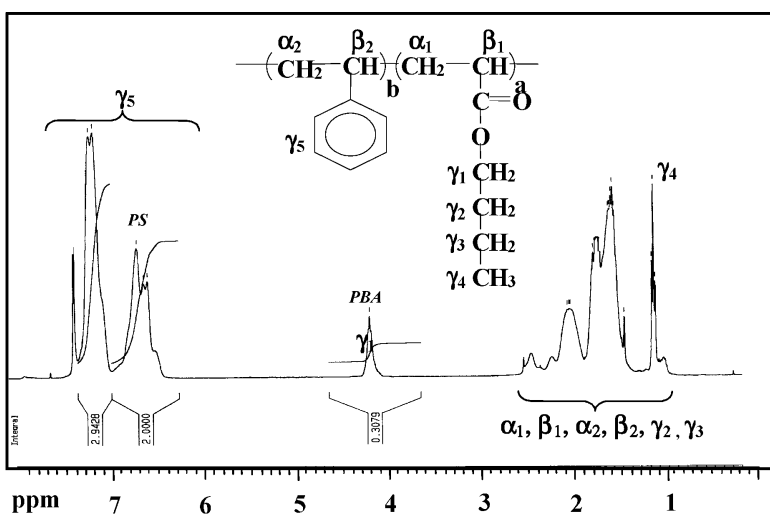

Figure 3. ${ }^{1} \mathrm{H}$ NMR spectrum of free diblock copolymer BA- $b-(\mathrm{S}-\mathrm{A})$.

transfer agent to stop the polymerization process. A study of the dye position in the macromolecular chains of oligomers is under way by NMR and mass spectroscopy. Nevertheless, the principal aim of this research is to elucidate the ability to generate alizarin grafted diblock copolymer from a mica surface, as described.

Characterization of the Free Chains by NMR. The ${ }^{1} \mathrm{H}$ NMR spectrum of the free copolymer in $\mathrm{CDCl}_{3}$ is shown in Figure 3.

The copolymer structure is demonstrated by the signal at 6-8 ppm, which corresponds to the phenyl groups of PS. This spectrum does not show peaks that characterize alizarin because the latter was in small quantity compared with PBA and PS ( 0.3 mol \% of alizarin per mole of Styrene). Nevertheless, the chain extension demonstrated by SEC and the presence of styrene units in the copolymer structure could be representative of the diblock copolymer structure. Integration of the peaks leads to the molar composition of the copolymer: $16 \% \mathrm{PBA}$ and $84 \% \mathrm{P}(\mathrm{S}-\mathrm{A})$. If one considers the value of $M_{\mathrm{n}}$ for the PBA macroinitiator $\left(M_{\mathrm{n}}=30000\right.$ $\left.\mathrm{g} \cdot \mathrm{mol}^{-1}\right)$, such a composition should correspond to $M_{\mathrm{n}}=$ $137000 \mathrm{~g} \cdot \mathrm{mol}^{-1}$ for the copolymer, which is in good agreement with the SEC results even if no characteristic bond between the two blocks can be observed. Indeed, in this architecture and with the degree of polymerization of the macromolecular chains $(\approx 200$ units of PBA and $\approx 1300$ units of PS), the chemical bond between the two blocks would represent only $1 / 1500$ unit, which corresponds to a very low value, undetectable in the polymeric system by NMR (Table 2).

Characterization of the Free Chains by UV-Vis Spectroscopy. The UV-vis spectra of the free chains of copolymer were also investigated. The comparison of the UV-vis spectrum of free block poly(BA- $b-(\mathrm{S}-\mathrm{A}))$ with those of poly $(\mathrm{BA}-b-\mathrm{S})$ (synthesized under the same conditions) and modified alizarin is represented in Figure 4.

The spectrum of free block copolymer shows the peak characteristic of PS at $257 \mathrm{~nm}$, a shoulder at about $280 \mathrm{~nm}$, and two small absorption bands at 329 and $390 \mathrm{~nm}$, which correspond to linked alizarin (see Figure 1). These bands indicate the incorporation of the dye-based monomer in the second PS block of the copolymer.

3.3. Characterization of the Mica-Copolymer Composite. Qualitative Composition of Hybrid InorganicOrganic Composite. At first the mica-copolymer composite 


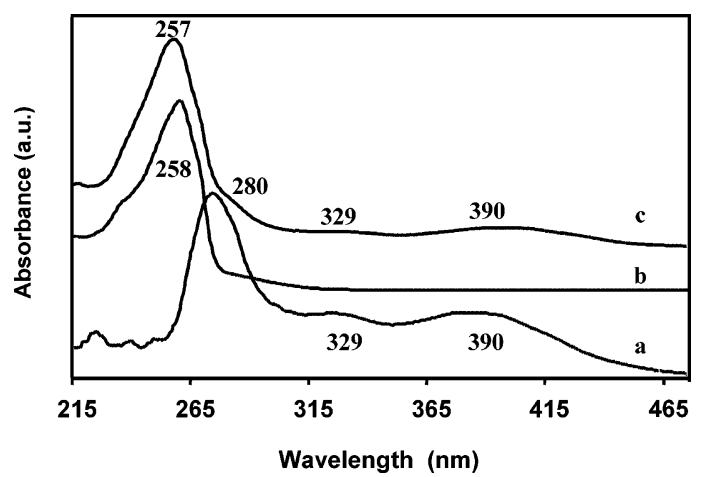

Figure 4. UV-vis spectra of (a) modified alizarin, (b) diblock copolymers $\mathrm{BA}-b-\mathrm{S}$, and (c) BA- $b-(\mathrm{S}-\mathrm{A})$.

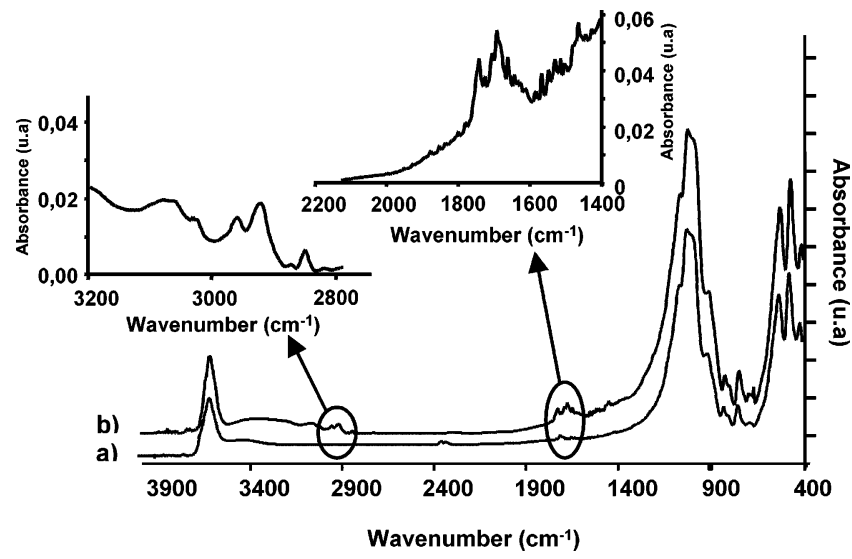

Figure 5. FTIR spectra of Soft Mica (a) and diblock copolymer BA-b(S-A)-mica composite (b).

was characterized qualitatively. A typical FTIR spectrum of the composite compared to the spectrum of Soft Mica (Figure $5)$ shows the presence of poly $(\mathrm{BA}-b-(\mathrm{S}-\mathrm{A}))$ on the surface of the mica. We can see the absorption band characteristic of siloxane bonds $\left(1100 \mathrm{~cm}^{-1}\right)$ of mica, the $\mathrm{CH}$ vibrations $\left(2800-3000 \mathrm{~cm}^{-1}\right)$ of aromatic styrene, and the absorption band due to the carbonyl function $\left(\nu_{\mathrm{C}=\mathrm{O}} 1735 \mathrm{~cm}^{-1}\right)$ of BA.

$T G A$. The adsorption density of copolymer on mica platelets can be calculated from the loss of weight of the composite which occurs in TGA experiments between 30 and $800{ }^{\circ} \mathrm{C}$ and corresponds to the degradation of the copolymer. The amount of adsorbed copolymer was found to be $0.107 \mathrm{mg}$ per $\mathrm{mg}$ of mica, which corresponds to 0.07 molecules per $\mathrm{nm}^{2}$ of mica surface.

It may be noted that the adsorption density of polymer chains is lower than that of the PBA macroinitiator on the mica surface $\left(0.6\right.$ molecule $\left./ \mathrm{nm}^{2}\right) .{ }^{16}$ This phenomenon is related to desorption of the macromolecular chains on a continuous expellation with time, probably due to an increase of affinity with the bulk. Indeed, when the polymer chains grow from the mica surface, the intermolecular interactions with the free macromolecular chains of the external solution must be higher than the ionic interactions between the end chains and the mica surface.

Thermal Behavior of Adsorbed Macromolecular Chains. The calorimetric behavior of the poly $(\mathrm{BA}-b-(\mathrm{S}-\mathrm{A}))$ bound to mica was scanned between -80 and $+160{ }^{\circ} \mathrm{C}$ at a rate of $10{ }^{\circ} \mathrm{C} / \mathrm{min}$. The DSC trace of the composite shows two glass transitions $\left(T_{\mathrm{g}}\right)$ at -42 and $+92{ }^{\circ} \mathrm{C}$ corresponding to the transitions of PBA and PS segments, respectively. These
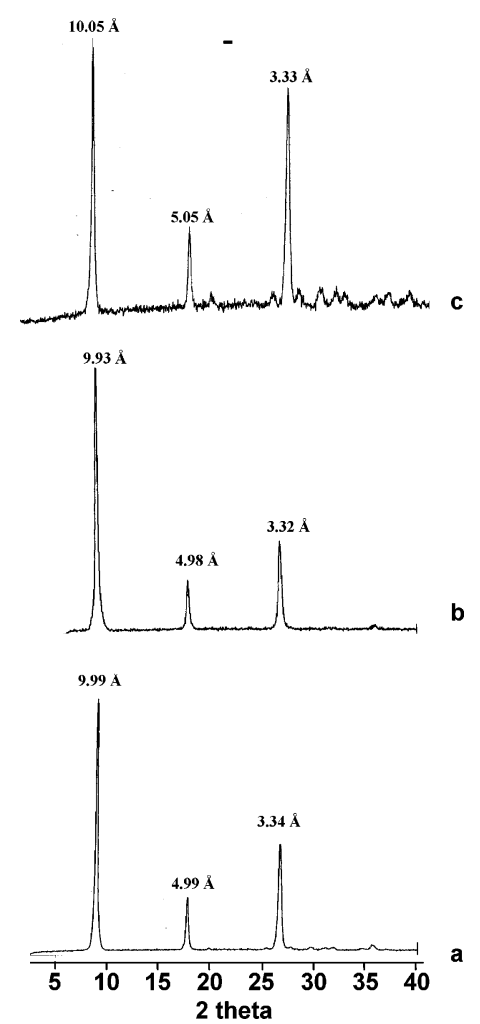

Figure 6. XRD patterns: (a) Soft Mica, (b) PBA-coated mica, and (c) diblock copolymer BA- $b-(\mathrm{S}-\mathrm{A})-$ mica composite.

results are in agreement with those obtained by SEC and also confirm the formation of the diblock copolymer. Indeed, the normal $T_{\mathrm{g}}$ of PBA is around $-55^{\circ} \mathrm{C}$. In this case, one of the ends of the PBA is adsorbed on the mica surface and the other end is covalently bonded to the PS segment of the diblock copolymer in a glassy state. In this type of organization, the PBA block is confined between two "solid" phases and $T_{\mathrm{g}}$ increases. On the other hand, the $T_{\mathrm{g}}$ of styrenealizarin is lower than that expected for pure PS of the same molecular weight. An identical effect has already been observed with BA- $b$-S diblock grafted silica particles, which demonstrates that it cannot be attributed to the presence of alizarin but more likely to the fact that one end of PS is linked to the "soft" phase of PBA, decreasing its $T_{\mathrm{g}}$ value. ${ }^{26}$

Optical Properties. XRD Analysis. Recalling that the main objective of this study is to create a polymer layer from the mica surface while preserving its lamellar structure, we must check if the layers of this structure are damaged during the process. An analysis by XRD was effected.

The XRD patterns of the resulting solid prepared by polymerization from the mica surface of PBA and the poly(BA- $b-(\mathrm{S}-\mathrm{A}))$ - mica composite are compared to that of mica in Figure 6.

In the different XRD patterns, it is observed that the peak corresponding to the (001) reflection of mica is not perturbed by the different pigment synthesis steps. The treatments carried out on the compound relative to mica do not seem to have affected its lamellar structure, preserving also its optical properties.

Color. The purpose of this study was to prepare new pigments with different colors from the substrate and to exhibit interferential effects. As shown by photographs a-c 


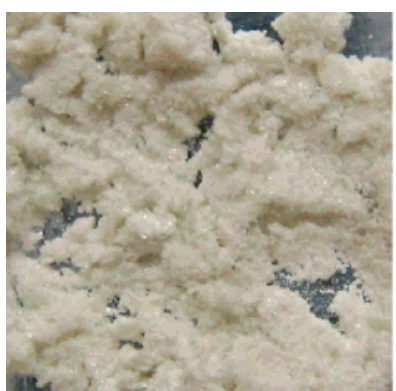

a

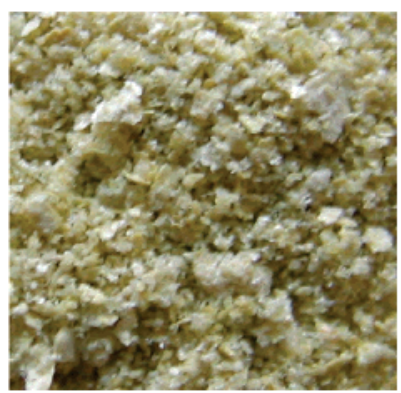

b

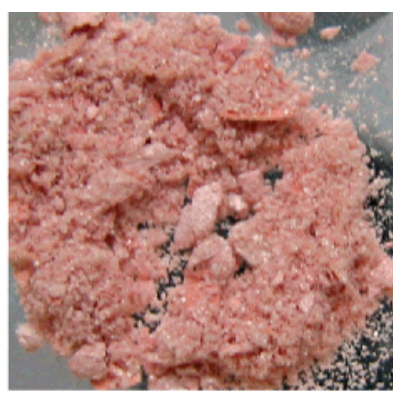

C

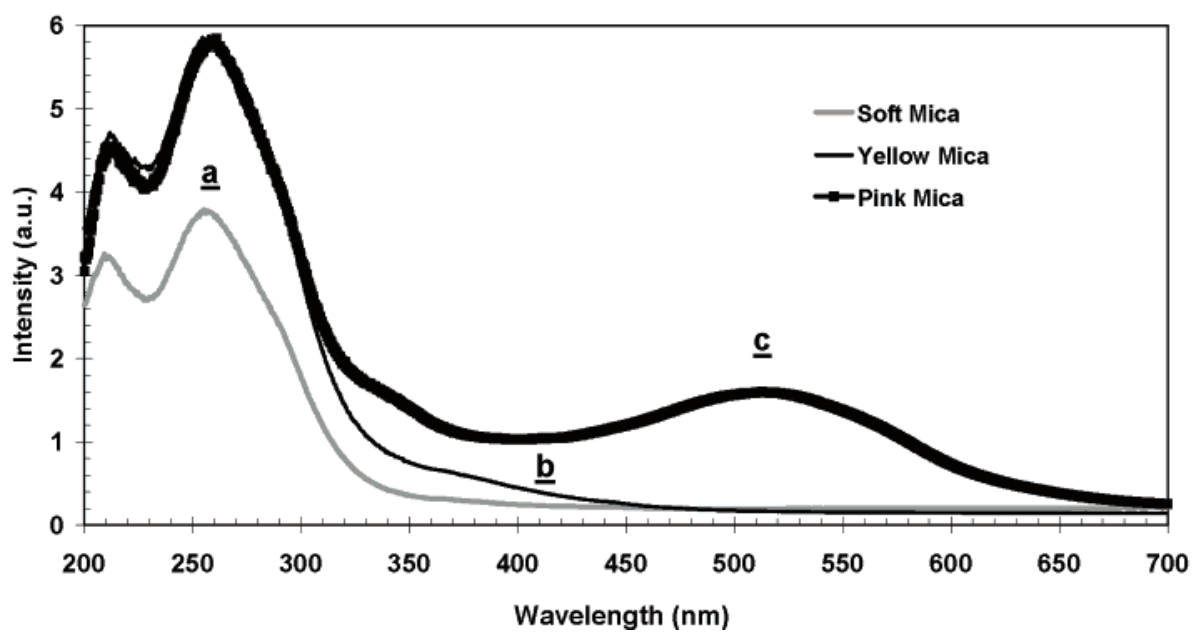

Figure 7. Photographs (top) and UV-vis spectra in the solid state (bottom) of (a) Soft Mica, (b) "yellow" PBA-mica, and (c) "pink" diblock copolymer BA- $b-(\mathrm{S}-\mathrm{A})-$ mica composite.

in Figure 7, the change of mica color by polymer and copolymer adsorption is quite remarkable.

First, on the basis of a "white" Soft Mica (Figure 7a), the adsorption of a layer of PBA on this silicate gave a "yellow" product (Figure $7 b$ ), which could be due to the effect of coating the mica by an adsorbed monolayer of polymer. Next, the addition of a new layer of S-A gave a "pink" composite (Figure 7c).

The color modification generated by the nature of the organic layer on the mica surface is confirmed by the UVvis spectra in the solid state. For the "white" Soft Mica, a classical adsorption spectrum is obtained with an intense peak centered at $260 \mathrm{~nm}$. When a PBA layer is coated on the mica surface, a broad adsorption peak appears from $450 \mathrm{~nm}$ with a maximum at $360 \mathrm{~nm}$, characteristic of a yellow coloration. Moreover, the poly(BA-b-(S-A)) layer shows an intense absorption at $510 \mathrm{~nm}$ and confirms the pink color of such a mica composite.

Considering that the free diblock copolymer poly(BA- $b$ $(\mathrm{S}-\mathrm{A})$ ) under the form of powder is yellow, the pink color of the mica copolymer composite is a quite surprising and interesting effect. Indeed, it may be due to the fact that, in the composite, the dye is influenced by the mica surface. As previously described in Table 1, the mica surface has a basic character and the dye color is pH-sensitive. It is concluded that the pink color corresponds to a local basic $\mathrm{pH}$ of the dye. Meanwhile, further experiments are under progress to understand this $\mathrm{pH}$ dependence and the spectroscopic behavior of the adsorbed dye.

From simple visual observation, no interference effects of these new pigments can be identified. At first, it is necessary to check the absence of such effects by using an adapted optical method. ${ }^{27}$ It seems well-verified, and several explanations can be proposed: (i) the difference between the refractive indices of the two polymer layers is not large enough $\left(n_{\mathrm{PS}}=1.55\right.$ and $\left.n_{\mathrm{PBA}}=1.47\right)$, (ii) the thickness of these layers is too small, and (iii) the expected high degree of segregation between the pure PBA sequences and the $\mathrm{P}(\mathrm{S}-\mathrm{A})$ sequence in this composition range of diblock copolymer of $16 \% \mathrm{PBA}$ and $84 \% \mathrm{P}(\mathrm{S}-\mathrm{A})$ is not present. Points ii and iii have to be consistent with the pink color of the copolymer mica composite attributed to the location of the dye in the immediate vicinity of the mica surface. Nevertheless, we demonstrate the ability of the NMP to generate block copolymers from the mica surface to elaborate a new pigment type based on mica.

\section{Conclusion}

This paper describes a relatively simple method for preparing organic/inorganic composites constituted of mica platelets and adsorbed layers of copolymers. We show that the color of mica is changed upon polymer adsorption, and when one of the copolymer sequences includes a dye, its color is influenced by the chemical properties of the mica surface. However, these new pigment types do not exhibit, at least visually, interferential effects. Neither the choice of the initial monomers nor the thickness of each sequence was optimized to produce such effects. From the general pathways described in this paper, it may be possible to obtain a

(27) Ghannam, L.; Billon, L.; Francois, J.; Shanahan, M. E. R.; Garay, H. In preparation. 
monitoring of the visual aspect of these pigments via selected experimental conditions of the in situ nitroxide-mediated copolymerization. Besides, we will show in a forthcoming paper that the control of the $\mathrm{pH}$ of platelet suspensions leads to the generation of pigments in a broad range of colors and the possibility to obtain good dispersion in polymer matrixes.

Acknowledgment. We would like to thank M.S. Bacou for her scientific contributions, A. Khoukh for NMR, and J.C. Dupin for XRD measurements. Special thanks are due to P. Maury from 2PSM "Propriétés Psychosensorielles des Matériaux" for his support and motivation.

Supporting Information Available: ${ }^{1} \mathrm{H}$ NMR spectrum used to calculate the average number of acrylic units per alizarin molecule. This material is available free of charge via the Internet at http://pubs.acs.org.

CM0478024 